\title{
Switching from entecavir to tenofovir disoproxil fumarate for HBeAg-positive chronic hepatitis B patients: a phase 4, prospective study
}

Fumitaka Suzuki ${ }^{1}$, Yoshiyuki Suzuki ${ }^{2}$, Yoshiyasu Karino ${ }^{3,22}$, Yasuhito Tanaka ${ }^{4,23}$, Masayuki Kurosaki ${ }^{5}$, Hiroshi Yatsuhashi ${ }^{6}$, Tomofumi Atarashi ${ }^{7}$, Masanori Atsukawa ${ }^{8}$, Tsunamasa Watanabe ${ }^{9}$, Masaru Enomoto ${ }^{10}$, Masatoshi Kudo ${ }^{11}$, Naoto Maeda ${ }^{12}$, Hiroshi Kohno ${ }^{13}$, Kouji Joko ${ }^{14}$, Kojiro Michitaka ${ }^{15}$, Koichiro Miki ${ }^{16,24}$, Kazuhiro Takahashi ${ }^{17}$, Tatsuya Ide ${ }^{18}$, Shigetoshi Fujiyama ${ }^{19}$, Tomoko Kohno ${ }^{20}$, Hiroshi Itoh ${ }^{20 \wedge}$, Sakiyo Tsukamoto ${ }^{20}$, Yuko Suzuki ${ }^{20}$, Yoshiaki Kawano ${ }^{20^{*}} \mathbb{B}$, Wataru Sugiura ${ }^{21}$ and Hiromitsu Kumada ${ }^{2}$

\begin{abstract}
Background: Tenofovir disoproxil fumarate (TDF) is widely used and recommended as first-line treatment for patients infected with the hepatitis B virus (HBV). However, current data are limited regarding the efficacy and safety of switching to TDF for the treatment of chronic hepatitis B in hepatitis B e-antigen (HBeAg)-positive patients who are virologically suppressed with another nucleos(t)ide analogue. The primary objective of this study was to evaluate the hepatitis B surface antigen (HBsAg) reduction potential of switching from entecavir (ETV) to TDF at week 48 in HBeAgpositive chronic hepatitis B patients with undetectable serum HBV-DNA.
\end{abstract}

Methods: In this multicenter, single-arm, open-label, phase 4 clinical study, 75 participants currently treated with ETV $0.5 \mathrm{mg}$ once daily were switched to TDF $300 \mathrm{mg}$ once daily for 96 weeks.

Results: At week 48, 3/74 participants (4\%) achieved $0.25 \log _{10}$ reduction of HBsAg levels from baseline (the primary endpoint). Mean HBsAg reduction was $-0.14 \log _{10} \mathrm{IU} / \mathrm{mL}$ and $12 \%$ (9/74) achieved $0.25 \log _{10}$ reduction by 96 weeks. No participants achieved HBsAg seroclearance. HBsAg reduction at weeks 48 and 96 was numerically greater in participants with higher alanine aminotransferase levels ( $\geq 60 \mathrm{U} / \mathrm{L}$ ). Seventeen participants (25\%) achieved HBeAg seroclearance up to week 96 . No participants experienced viral breakthrough. All drug-related adverse events (18 participants [24\%]) were mild in intensity, including an increase in urine beta-2-microglobulin (15 participants [20\%]).

Conclusions: In conclusion, HBsAg reduction was limited after switching from ETV to TDF in this study population. Further investigation is warranted to better understand the clinical impact of switching from ETV to TDF.

ClinicalTrials.gov: NCT03258710 registered August 21, 2017. https://clinicaltrials.gov/ct2/show/NCT03258710?term= NCT03258710\&draw $=2 \&$ rank $=1$

\footnotetext{
*Correspondence: yoshiaki.x.kawano@gsk.com

${ }^{20}$ GlaxoSmithKline K.K., Akasaka Intercity AIR, 1-8-1, Akasaka, Minato-ku,

Tokyo 107-0052, Japan

Full list of author information is available at the end of the article

^Hiroshi Itoh: Deceased
}

(C) The Author(s) 2021. Open Access This article is licensed under a Creative Commons Attribution 4.0 International License, which permits use, sharing, adaptation, distribution and reproduction in any medium or format, as long as you give appropriate credit to the original author(s) and the source, provide a link to the Creative Commons licence, and indicate if changes were made. The images or other third party material in this article are included in the article's Creative Commons licence, unless indicated otherwise in a credit line to the material. If material is not included in the article's Creative Commons licence and your intended use is not permitted by statutory regulation or exceeds the permitted use, you will need to obtain permission directly from the copyright holder. To view a copy of this licence, visit http://creativecommons.org/licenses/by/4.0/. The Creative Commons Public Domain Dedication waiver (http://creativeco mmons.org/publicdomain/zero/1.0/) applies to the data made available in this article, unless otherwise stated in a credit line to the data. 
Keywords: Tenofovir disoproxil fumarate, Chronic hepatitis B, HBsAg, HBeAg-positive, Entecavir

\section{Background}

Hepatitis B virus (HBV) infection is characterized by the serologic presence of hepatitis $B$ e-antigen ( $\mathrm{HBeAg}$ ) and HBV-DNA, as well as hepatitis B surface antigen (HBsAg) [1]. Oral nucleos(t)ide analogues (NAs) such as lamivudine, entecavir (ETV), tenofovir alafenamide (TAF), and tenofovir disoproxil fumarate (TDF) effectively inhibit reverse transcription of pregenomic HBVRNA, thereby lowering serum HBV-DNA levels $[2,3]$. Achieving HBsAg seroclearance is associated with sustained immunologic and virologic control by appropriate treatments and a reduced risk of hepatocellular carcinoma (HCC) [4-6]. While the long-term treatment goal of HBsAg seroclearance is rarely achievable with current treatment options, including NAs [7, 8], several clinical trials have been conducted to seek better treatment options to approach HBsAg seroclearance [9-11].

Regarding HCC risk during treatment with NAs, a study in Korea indicated that treatment with TDF has been associated with a significantly lower risk of HCC compared with ETV in chronic hepatitis B (CHB) patients [12]. Moreover, previous studies in $\mathrm{CHB}$ patients conducted by our group demonstrated superior $\mathrm{HBsAg}$ reduction with TDF compared with other NAs in NAnaïve patients. In addition, reduction in $\mathrm{HBsAg}$ was previously achieved predominantly in HBeAg-positive patients with relatively high viral activity who were receiving TDF $[4,13]$.

Previous studies, mainly in HBeAg negative patients, have reported short-term efficacy after switching from ETV to TDF [11, 14]. However, current data are limited, focusing on $\mathrm{HBeAg}$-positive patients with $\mathrm{CHB}$ who are virologically suppressed with another NA. Furthermore, the impact of patient factors on the reduction of HBsAg remains unclear $[13,15]$. Based on previous studies showing a decline of $\mathrm{HBsAg}$ in patients with $\mathrm{HBeAg}$ positive $\mathrm{CHB}$ and undetectable serum HBV-DNA who were treated with ETV therapy, we predicted that HBsAg reduction after switching from ETV to TDF could potentially be of clinical benefit.

\section{Methods}

\section{Study design}

This was a multicenter, single-arm, open-label clinical study conducted in $\mathrm{HBeAg}$-positive $\mathrm{CHB}$ patients with undetectable serum HBV-DNA (initiated October 2, 2017 and completed November 25, 2019). Participants $(\mathrm{N}=75)$ currently treated with ETV $0.5 \mathrm{mg}$ once daily were switched to TDF $300 \mathrm{mg}$ on day 1 , following a 6-week screening period. TDF was administered once daily for 96 weeks.

The study was approved by the ethics committee at every participating institution (19 centers in Japan) and was conducted according to the recommendations of Good Clinical Practice and the Declaration of Helsinki (2013). All participants provided written informed consent to participate in the study.

\section{Study participants}

Male and female patients with CHB between 20 and 69 years of age at the time of informed consent who had been treated with ETV for at least two years were eligible for study inclusion. At screening, participants were required to test positive for serum HBeAg (local hospital or central laboratory), have an HBV-DNA level below the limit of quantitation $\left(<1.3 \log _{10} \mathrm{IU} / \mathrm{mL}[<20 \mathrm{IU} /\right.$ $\mathrm{mL}]$ ), and have a serum HBsAg level $\geq 800 \mathrm{IU} / \mathrm{mL}$ (or 80 to $800 \mathrm{IU} / \mathrm{mL}$ and fluctuation decrease within $0.1 \log _{10}$ $\mathrm{IU} / \mathrm{mL}$ per year to exclude participants with continuous $\mathrm{HBs} A \mathrm{~g}$ decrease). Additional inclusion criteria included creatinine clearance $\geq 70 \mathrm{~mL} / \mathrm{min}$, hemoglobin $\geq 8 \mathrm{~g} / \mathrm{dL}$, and white blood cell count $\geq 1000 / \mathrm{mm}^{3}$.

Patients who received any interferon (IFN) or HBV vaccine therapy within 24 weeks prior to initiation of the study treatment; or TDF, adefovir dipivoxil (ADV), or TAF within two years prior were excluded. Patients coinfected with HIV or hepatitis $\mathrm{C}$ virus $(\mathrm{HCV})$ were excluded. Patients with a history of (or suspected of having) $\mathrm{HCC}$ were also ineligible. Other exclusion criteria included drugs causing renal impairment, competitors of

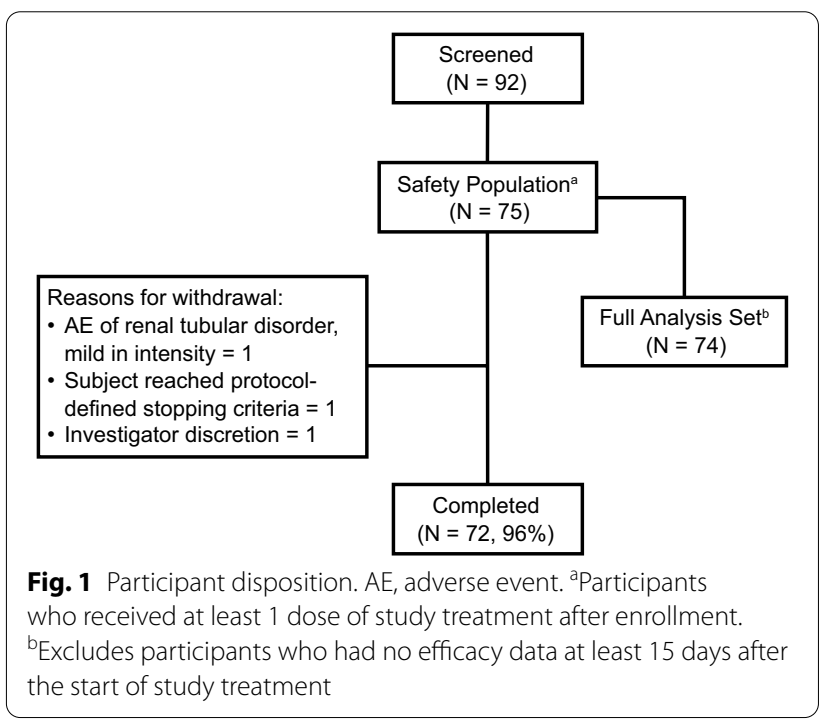


Table 1 Participant demographics and baseline characteristics (SP)

\begin{tabular}{|c|c|}
\hline Baseline characteristic & TDF $(\mathrm{N}=75)$ \\
\hline Age (years), mean ( $\pm S D$ ) & $48.4( \pm 9.35)$ \\
\hline \multicolumn{2}{|l|}{ Sex, n (\%) } \\
\hline Male & $55(73)$ \\
\hline Female & $20(27)$ \\
\hline \multicolumn{2}{|l|}{ Race, n (\%) } \\
\hline Japanese & $71(95)$ \\
\hline East Asian & $4(5)$ \\
\hline \multicolumn{2}{|l|}{ HBV genotype, n (\%) } \\
\hline A & $1(1)$ \\
\hline B & $2(3)$ \\
\hline C & $72(96)$ \\
\hline HBV-DNA $\left(\log _{10} \mathrm{IU} / \mathrm{mL}\right)$, mean $( \pm S D)$ & $0.92( \pm 0.12)$ \\
\hline $\operatorname{ALT}(I \cup / L)$, mean $( \pm S D)$ & $23.5( \pm 18.13)$ \\
\hline \multicolumn{2}{|l|}{ HBeAg, n (\%) } \\
\hline Positive & $70(93)$ \\
\hline Negative $^{a}$ & $5(7)$ \\
\hline $\mathrm{HBsAg}(\mathrm{IU} / \mathrm{mL})$, mean $( \pm \mathrm{SD})$ & $5311.3( \pm 5619.84)$ \\
\hline $\mathrm{HBcrAg}\left(\log _{10} \mathrm{U} / \mathrm{mL}\right)$, mean $( \pm \mathrm{SD})$ & $5.5( \pm 0.55)$ \\
\hline \multicolumn{2}{|l|}{ eGFR by JSN-CKDI (mL/min/1.73m²), n (\%) } \\
\hline$<60$ & $0(0)$ \\
\hline 60 to $<90$ & $42(56)$ \\
\hline$\geq 90$ & $33(44)$ \\
\hline Urine beta-2-microglobulin ( $\mu \mathrm{g} / \mathrm{g} \mathrm{Cr})$, mean $( \pm \mathrm{SD})$ & $241.9(305.58)$ \\
\hline \multicolumn{2}{|l|}{ Protocol defined liver cirrhosis, n (\%) } \\
\hline Yes & $0(0)$ \\
\hline No & $75(100)$ \\
\hline
\end{tabular}

ALT alanine aminotransferase, $C r$ creatinine, eGFR by JSN-CKDI estimated glomerular filtration rate calculated by the Japanese Society of NephrologyChronic Kidney Disease Initiatives equation, $\mathrm{HBV}$ hepatitis $\mathrm{B}$ virus, $\mathrm{HBeAg}$ hepatitis B e-antigen, $H B s A g$ hepatitis $B$ surface antigen, $H B c r A g$ hepatitis $B$ core-related antigen, $S D$ standard deviation, $S P$ safety population, TDF tenofovir disoproxil fumarate

${ }^{\text {a }} \mathrm{HBeAg}$-positive according to local in-hospital laboratory results, but $\mathrm{HBeAg}$ negative according to central laboratory results at screening

renal excretion, immunosuppressants, or glucocorticoids within eight weeks prior to study initiation; the presence of proximal tubulopathy; decompensated $\mathrm{CHB}$ (direct bilirubin $>1.5 \times$ the upper limit of normal; prothrombin time $<60 \%$; platelets $<75,000 / \mathrm{mm}^{3}$; albumin $<3.0 \mathrm{~g} / \mathrm{dL}$ ); or a history of alcohol or drug abuse.

\section{Clinical evaluations}

Virologic testing at the time of screening included HIV, $\mathrm{HCV}, \mathrm{HBV}$ genotype, HBV-DNA levels, HBeAg/anti$\mathrm{HBe}$, and HBsAg/anti-HBs quantitation. HBV-DNA, $\mathrm{HBeAg}$ /anti-HBe, HBsAg/anti-HBs, and hepatitis B core-related antigen ( $\mathrm{HBcrAg}$ ) testing was performed at week 4 , week 12 , and every 12 weeks thereafter, by
SRL Medisearch Inc. (Tokyo, Japan). Dual energy X-ray absorptiometry (DXA) testing was performed at screening, last visit, and at intervals as needed based on laboratory results, but not more frequently than every 4 months.

\section{Study endpoints}

The primary endpoint of this study was the proportion of participants achieving $0.25 \log _{10} \mathrm{HBsAg}$ reduction from baseline at week 48 (defined as the $\mathrm{HBsAg}$ responder rate). The secondary endpoint was the proportion of participants achieving $0.25 \log _{10} \mathrm{HBs} \mathrm{Ag}$ reduction from baseline at weeks 24 and 96. Additional secondary efficacy analyses at weeks 24, 48, and 96 included the proportion of participants achieving HBsAg seroclearance and $\mathrm{HBsAg} /$ anti-HBs seroconversion, reduction of HBsAg from baseline, the proportion of participants achieving $\mathrm{HBeAg}$ seroclearance and $\mathrm{HBeAg} / \mathrm{anti}-\mathrm{HBe}$ seroconversion, and reduction of $\mathrm{HBcrAg}$ from baseline.

Safety assessments included the monitoring of adverse events (AEs), as well as urinalysis, hematology, and clinical chemistry testing, which was performed at baseline and again at weeks 4 and 12, and every 12 weeks thereafter. Adverse events were summarized as study drugrelated AEs, AEs by intensity, and those resulting in discontinuation of the study. Adverse events of special interest (AESIs) included those with renal, liver, or bone involvement.

\section{Statistical analyses}

Descriptive statistics were used to assess the efficacy and safety objectives. An estimation approach was used to address the efficacy objectives, where point estimates and corresponding 95\% confidence intervals (CIs) were constructed.

Although no confirmatory hypotheses were tested in this study, the sample size was based on the expected responder rate and threshold rate. Results from the previous Japanese phase 3 study [13] showed that the proportion of participants expected to achieve $0.25 \log _{10} \mathrm{HBsAg}$ reduction from the baseline at week 48 was $20 \%$. Additionally, a $0.25 \log _{10}$ HBsAg reduction after 48 weeks of TDF therapy was considered to be clinically meaningful and defined as a primary endpoint in this study. The proportion of HBsAg responders in subjects not switched to TDF-based regimens on the basis of results of ETV treatment was assumed to be $6 \%$ (threshold rate), and the sample size with at least $90 \%$ power to detect a $14 \%$ difference against the threshold was calculated to be 57 . Allowing for a participant dropout rate of $10 \%$, the target sample size was set at approximately 65 . 
Table 2 Antiviral responses after 48 and 96 weeks of treatment (FAS)

\begin{tabular}{|c|c|c|c|}
\hline Key efficacy endpoints & Baseline & Week 48 & Week 96 \\
\hline \multicolumn{4}{|l|}{ Positive HBsAg at baseline $(\mathrm{N}=74)$} \\
\hline \multicolumn{4}{|l|}{ Participants achieving $0.25 \log _{10} \mathrm{HBsAg}$ reduction from baseline } \\
\hline $\mathrm{HBsAg} \leq-0.25 \log _{10}, \mathrm{n}(\%),[95 \% \mathrm{Cl}]$ & - & $3(4),[0.8,11.4]$ & $9(12),[5.7,21.8]$ \\
\hline Participants achieving HBsAg seroclearance & & 0 & 0 \\
\hline Participants achieving HBsAg/anti-HBs seroconversion ${ }^{a}$ & & 0 & 0 \\
\hline \multicolumn{4}{|l|}{ Change from baseline in $\mathrm{HBsAg}\left(\log _{10} \mathrm{IU} / \mathrm{mL}\right)$} \\
\hline Mean (SD), [95\% Cl] & $3.52(0.46),[3.41,3.62]^{b}$ & $-0.11(0.08),[-0.13,-0.10]^{c}$ & $-0.14(0.12),[-0.17,-0.11]^{\mathrm{a}}$ \\
\hline \multicolumn{4}{|l|}{ Positive HBeAg at baseline $(\mathrm{N}=69)$} \\
\hline Participants achieving HBeAg seroclearance, n (\%) & & $8(12)$ & $17(25)$ \\
\hline Participants achieving HBeAg/anti-HBe seroconversion, ${ }^{d} n(\%)$ & & $7(13)$ & $13(25)$ \\
\hline \multicolumn{4}{|l|}{ Change from baseline in $\mathrm{HBcrAg}(\mathrm{N}=74),\left(\log _{10} \mathrm{U} / \mathrm{mL}\right)$} \\
\hline Mean (SD), [95\% Cl] & $5.53(0.54),[5.40,5.65]^{b}$ & $-0.17(0.29),[-0.23,-0.10]^{c}$ & $-0.30(0.36),[-0.38,-0.22]^{a}$ \\
\hline \multicolumn{4}{|l|}{ Change from baseline in HBV-DNA $(N=74),\left(\log _{10} \mathrm{IU} / \mathrm{mL}\right)$} \\
\hline Mean (SD), [95\% Cl] & $0.92(0.12),[0.89,0.95]^{b}$ & $-0.02(0.10),[-0.04,0.01]^{c}$ & $-0.02( \pm 0.12),[-0.05,0.01]^{a}$ \\
\hline \multicolumn{4}{|c|}{$\begin{array}{l}\text { Anti-HBe anti-hepatitis B e-antibody, } F A S \text { full analysis set, } A n t i-H B s \text { hepatitis B surface antibody, } C l \text { confidence interval, } H B e A g \text { hepatitis B e-antigen, } H B C r A g \text { hepatitis B } \\
\text { core-related antigen, } H B s A g \text { hepatitis B surface antigen, } H B V \text { hepatitis B virus, } S D \text { standard deviation, TDF tenofovir disoproxil fumarate }\end{array}$} \\
\hline \multicolumn{4}{|c|}{${ }^{\mathrm{a}}$ The mean and SD baseline values are absolute values } \\
\hline \multicolumn{4}{|l|}{${ }^{\mathrm{b}} \mathrm{N}=74$} \\
\hline${ }^{\mathrm{C}} \mathrm{N}=73$ & & & \\
\hline
\end{tabular}

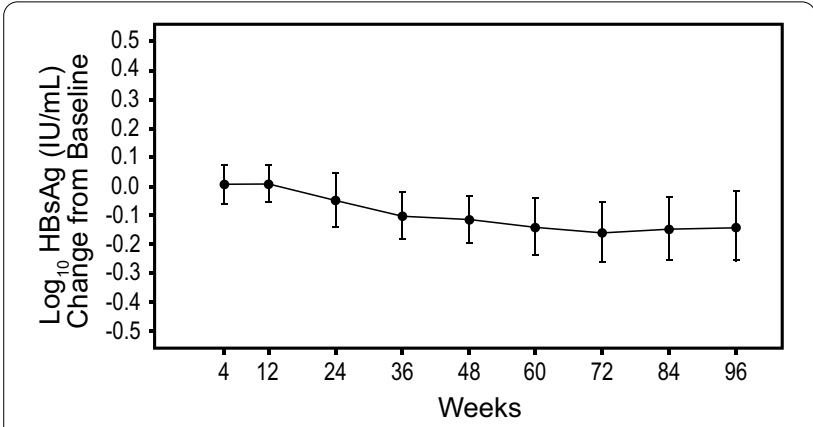

Fig. 2 Mean change in HBsAg up to week 96 (FAS). FAS, full analysis set; $\mathrm{HBs} A g$, hepatitis B surface antigen

Analyses of safety data were performed at screening, baseline, weeks 4, 12, 24, 36, 48 and week 96 using the safety population, defined as all participants who received study treatment. Analyses of efficacy data were performed at screening, baseline, weeks 4, 12, 24, 36, 48, and week 96 using the full analysis set (FAS), defined as all participants enrolled who received study treatment and who had efficacy data available at least 15 days after starting treatment. A subset of participants, which excluded three participants in the FAS who met the protocol deviation criteria of receiving medication, was defined as the efficacy evaluable set (EES). Analysis of the EES was performed to evaluate the robustness of the efficacy results.

\section{Results}

A total of 92 patients were screened and 75 patients enrolled in the study (safety population) (Fig. 1).

The FAS included 74 participants, 72 of whom completed week 96. One participant withdrew from the study due to a study drug-related adverse event, one participant reached protocol-defined liver stopping criteria (bilirubin $\geq 2 \times$ the upper limit of normal and direct bilirubin $>35 \%$ ) on day 1 before receiving TDF, and one participant was withdrawn at the discretion of the investigator.

\section{Participant characteristics}

Of the 75 participants (SP), 70 were $\mathrm{HBeAg}$-positive at baseline. Another five participants who were $\mathrm{HBeAg}$ positive at screening according to local in-hospital laboratory results were $\mathrm{HBeAg}$-negative at screening and baseline according to central laboratory results. For all participants, serum HBV-DNA level was undetectable $\left(<1.3 \log _{10} \mathrm{IU} / \mathrm{mL}[<20 \mathrm{IU} / \mathrm{mL}]\right)$ at baseline except for one participant with $1.9 \log _{10} \mathrm{IU} / \mathrm{mL}$. No patients met protocol-defined criteria for liver cirrhosis at baseline. Baseline characteristics for the safety population are shown in Table 1.

\section{Antiviral responses}

The proportion of participants achieving $0.25 \log _{10}$ HBsAg reduction from baseline at week 48 was $3 / 74$ (4\%) participants (Table 2). All three participants were 


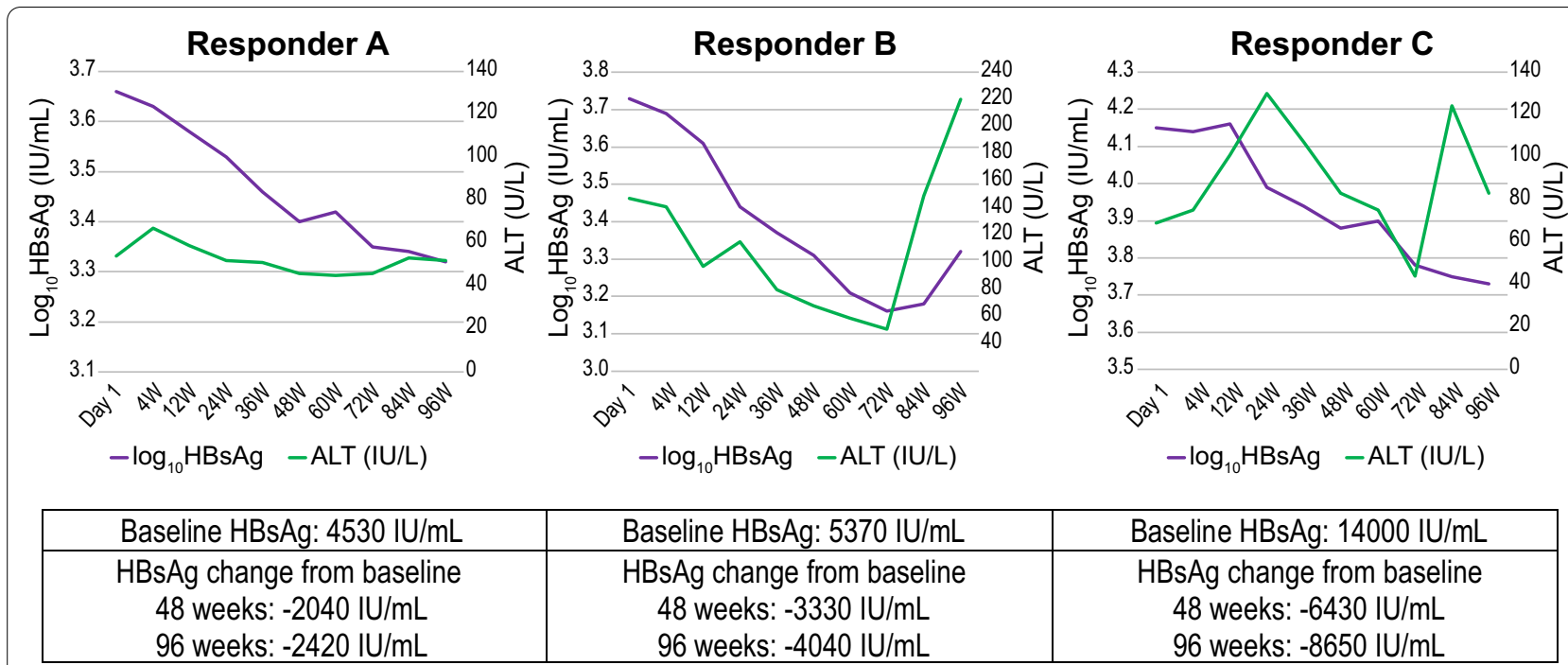

Fig. 3 Individual Responder Change in HBsAg and ALT (FAS). ALT, alanine aminotransferase; FAS, full analysis set; HBsAg, hepatitis B surface antigen; W, weeks

male, infected with HBV genotype $\mathrm{C}$, and were similar in age $(45,44$, and 42 years). One of these participants was $\mathrm{HBeAg}$-negative at baseline but was judged $\mathrm{HBeAg}$-positive according to a local laboratory at screening. At 96 weeks, the proportion of participants achieving $>0.25 \log _{10}$ reduction from baseline was $12 \%$ (9/74, including the three participants who had responded by week 48 ).

The overall mean ( \pm standard deviation $[S D])$ change from baseline in HBsAg level decreased, with a mean change of $-0.11( \pm 0.08) \log _{10} \mathrm{IU} / \mathrm{mL}$ at week 48 and $-0.14( \pm 0.12) \log _{10} \mathrm{IU} / \mathrm{mL}$ at week 96 (Table 2 and Fig. 2).

At weeks 48 and 96, HBsAg reduction from baseline was numerically greater in the higher alanine aminotransferase (ALT) group (defined as $\geq 60 \mathrm{U} / \mathrm{L}$ at least once from baseline) compared with the lower ALT group (defined as $<60 \mathrm{U} / \mathrm{L}$ from baseline). Mean $( \pm \mathrm{SD}$; [95\% CI]) change in HBsAg from baseline at week 48 was $-0.25( \pm 0.09 ;[-0.35,-0.15]) \log _{10} \mathrm{IU} / \mathrm{mL}$ in the higher ALT group $(\mathrm{N}=6)$, versus $-0.10( \pm 0.07$; $[-0.12,-0.08]) \log _{10} \mathrm{IU} / \mathrm{mL}$ in the lower ALT group $(\mathrm{N}=67)$. At week 96 , mean change from baseline in HBsAg was $-0.37( \pm 0.14 ;[-0.52,-0.22])$ in the higher ALT group $(\mathrm{N}=6)$ and $-0.12( \pm 0.09 ;[-0.14,-0.09])$ in the lower ALT group $(\mathrm{N}=66)$. All three participants who achieved $0.25 \log _{10}$ HBsAg reduction from baseline at week 48 demonstrated high serum ALT levels throughout the study period as shown in Fig. 3.

Of the additional six participants who achieved 0.25 $\log _{10}$ HBsAg reduction from baseline by week 96 , two were in the higher ALT group. No patients achieved HBsAg seroclearance up to week 96 (Table 2).

HBeAg seroclearance was analyzed in the 69 participants who were $\mathrm{HBeAg}$-positive at baseline. Eight participants (12\%) achieved HBeAg seroclearance up to week 48 and 17 participants (25\%) achieved HBeAg seroclearance by week 96 . $\mathrm{HBeAg} /$ anti-HBe seroconversion was analyzed in the 53 participants who were $\mathrm{HBeAg}$-positive and anti-HBe-negative at baseline, and was achieved by seven participants (13\%) up to week 48 and 13 participants (25\%) by week 96 .

The mean $( \pm \mathrm{SD}) \mathrm{HBcrAg}$ change from baseline was $-0.17( \pm 0.29) \log _{10} \mathrm{U} / \mathrm{mL}$ at week 48 and $-0.30( \pm 0.36)$ at week 96. No virologic breakthrough was observed, and serum HBV-DNA levels remained undetectable $\left(<1.3 \log _{10} \mathrm{IU} / \mathrm{mL}[<20 \mathrm{IU} / \mathrm{mL}]\right)$ through week 96 in all participants.

\section{Safety}

Adverse events and other key safety analyses are summarized in Table 3.

Overall, through week 96, most AEs were mild in severity. Two serious AEs, osteoarthritis (one participant) and appendicitis (one participant), were reported but neither was considered to be study drug-related. Drug-related AEs included renal tubular dysfunction and prothrombin time prolonged (one participant each), which were mild in intensity. One participant was withdrawn at the judgment of the investigator due to renal tubular disorder of mild intensity, which resolved. An increase in urine beta2-microglobulin, considered a sensitive and specific indicator of renal tubular dysfunction associated with TDF 
Table 3 Key safety endpoints (SP)

\begin{tabular}{|c|c|c|c|}
\hline \multicolumn{3}{|l|}{ Adverse events (week 96) } & \multirow{2}{*}{$\begin{array}{l}\text { TDF (N=75) } \\
\mathbf{n}(\%) \\
58(77)\end{array}$} \\
\hline \multicolumn{3}{|l|}{ On-therapy AE } & \\
\hline \multicolumn{3}{|l|}{ On-therapy serious AE } & $2(3)$ \\
\hline \multicolumn{3}{|c|}{ On-therapy AE leading to study withdrawal } & $1(1)$ \\
\hline \multicolumn{3}{|c|}{ Drug-related AE } & $18(24)$ \\
\hline \multicolumn{3}{|c|}{ Drug-related urine beta-2-microglobulin increase } & $15(20)$ \\
\hline \multicolumn{3}{|c|}{ Renal tubular disorder } & $1(1)$ \\
\hline \multicolumn{3}{|l|}{ Renal tubular dysfunction } & $1(1)$ \\
\hline \multicolumn{3}{|l|}{ Prothrombin time prolonged } & $1(1)$ \\
\hline Other key safety endpoints & $\mathbf{n}$ & Median (min, max) & $\begin{array}{l}\text { Median change from } \\
\text { baseline (min, max) }\end{array}$ \\
\hline \multicolumn{4}{|l|}{ Serum creatinine (mg/dL) } \\
\hline Baseline & 75 & $0.70(0.38,1.01)$ & \\
\hline Week 4 & 75 & $0.71(0.44,1.02)$ & $0.01(-0.14,0.20)$ \\
\hline Week 24 & 74 & $0.74(0.41,1.05)$ & $0.02(-0.08,0.15)$ \\
\hline Week 48 & 73 & $0.72(0.42,1.09)$ & $0.04(-0.11,0.12)$ \\
\hline Week 96 & 72 & $0.76(0.45,1.02)$ & $0.06(-0.10,0.17)$ \\
\hline \multicolumn{4}{|c|}{ eGFR by JSN-CKDI (mL/min/1.73m²) } \\
\hline Baseline & 75 & $86(60,135)$ & \\
\hline Week 4 & 75 & $84(60,138)$ & $-2.0(-21,20)$ \\
\hline Week 24 & 74 & $81(57,124)$ & $-3.0(-21,13)$ \\
\hline Week 48 & 73 & $82(56,124)$ & $-6.0(-20,12)$ \\
\hline Week 96 & 72 & $79.0(52,118)$ & $-9.5(-24,14)$ \\
\hline \multicolumn{4}{|c|}{ Urine beta-2-microglobulin ratio ( $\mu \mathrm{g} / \mathrm{g}$ creatinine) } \\
\hline Baseline & 75 & $154.91(40.71,1636.09)$ & \\
\hline Week 4 & 75 & $198.91(25.72,4779.66)$ & $45.02(-317.50,3143.57)$ \\
\hline Week 24 & 74 & $185.88(8.93,9006.76)$ & $41.17(-361.52,7890.23)$ \\
\hline Week 48 & 73 & $192.50(13.02,10,546.26)$ & $38.16(-582.24,9429.72)$ \\
\hline Week 96 & 72 & $154.96(11.20,9052.18)$ & $15.19(-166.80,7935.65)$ \\
\hline Serum phosphorus (mg/dL) & & & \\
\hline Baseline & 75 & $3.3(1.9,4.4)$ & \\
\hline Week 4 & 75 & $3.2(2.0,4.4)$ & $-0.10(-1.0,0.9)$ \\
\hline Week 24 & 74 & $3.3(1.4,4.5)$ & $-0.10(-1.1,1.4)$ \\
\hline Week 48 & 73 & $3.3(2.0,4.7)$ & $0.00(-1.3,0.9)$ \\
\hline Week 96 & 72 & $3.4(2.2,4.5)$ & $0.10(-1.1,1.2)$ \\
\hline$\% \mathrm{TRP}$ & & & \\
\hline Baseline & 75 & $89.92(77.91,97.71)$ & \\
\hline Week 4 & 75 & $88.49(77.04,98.79)$ & $-0.69(-13.26,6.75)$ \\
\hline Week 24 & 74 & $90.20(78.96,96.26)$ & $-0.52(-11.81,9.75)$ \\
\hline Week 48 & 73 & $89.44(81.51,97.71)$ & $0.17(-8.71,8.27)$ \\
\hline Week 96 & 72 & $89.83(81.07,96.90)$ & $-0.818(-10.25,15.47)$ \\
\hline $\operatorname{ALT}(U / L)$ & & & \\
\hline Baseline & 75 & $19.0(7,147)$ & \\
\hline Week 4 & 75 & $22.0(8,141)$ & $4.0(-14,60)$ \\
\hline Week 24 & 74 & $22.5(10,130)$ & $4.0(-32,61)$ \\
\hline Week 48 & 73 & $23.0(12,83)$ & $4.0(-79,23)$ \\
\hline Week 96 & 72 & $21.5(11,220)$ & $2.5(-20,73)$ \\
\hline
\end{tabular}


Table 3 (continued)

\begin{tabular}{|c|c|c|c|}
\hline BMD safety endpoints & $\mathbf{n}$ & Median (min, max) & $\begin{array}{l}\text { Median \% change } \\
\text { from baseline (min, } \\
\text { max) }\end{array}$ \\
\hline \multicolumn{4}{|l|}{$\mathrm{BMD}$, femur $\left(\mathrm{g} / \mathrm{cm}^{2}\right)$} \\
\hline Baseline & 23 & $0.83(0.64,0.99)$ & \\
\hline Week 96 & 23 & $0.80(0.66,1.00)$ & $-2.09(-12.67,6.59)$ \\
\hline \multicolumn{4}{|c|}{ BMD, lumbar vertebra $\left(\mathrm{g} / \mathrm{cm}^{2}\right)$} \\
\hline Baseline & 75 & $1.00(0.63,1.43)$ & \\
\hline Week 96 & 72 & $0.96(0.64,1.52)$ & $-2.24(-12.21,6.73)$ \\
\hline
\end{tabular}

$[8,16,17]$, was the only renal $\mathrm{AE}$ that was reported in more than one participant. An increase of mild intensity occurred in 15 participants $(20 \%)$ and considered to be study drug-related.

In addition to the increase in median urine beta-2-microglobulin (median change from baseline $15.19 \mu \mathrm{g} / \mathrm{g}$ creatinine), a small increase in median serum creatinine $(0.06 \mathrm{mg} / \mathrm{dL})$ and a decrease in median estimated glomerular filtration rate $\left(\mathrm{eGFR},-9.5 \mathrm{~mL} / \mathrm{min} / 1.73 \mathrm{~m}^{2}\right.$ ) were observed at week 96. Not all participants with an increase in urine beta-2-microglobulin experienced a decrease in eGFR, and there were no decreases in median percent renal tubular reabsorption of phosphate (\%TRP) or serum phosphorus except for two participants who experienced hypophosphatemia, which were not considered to be study drug-related. Overall, there were three types of clinical courses observed amongst participants who experienced a change in renal parameters (Fig. 4): 1) participants with an increase in urine beta-2-microglobulin and decrease in eGFR (Fig. 4a), 2) those with an increase in urine beta-2-microglobulin and without change in eGFR (Fig. 4b), and 3) those without a change in urine beta-2-microglobulin and decrease in eGFR (Fig. 4c).

No participants had drug-related liver AEs. The only liver AESI was hepatic steatosis, not drug related, reported by one participant. No clinically significant elevation of ALT was observed (Table 3). At baseline, six participants (8\%) had ALT levels above the upper limit of normal (> $40 \mathrm{U} / \mathrm{L})$ compared with 10 participants $(14 \%)$ at week 48 and five (7\%) at week 96.

No participants had drug-related bone AEs or AESIs. The only bone AESI was jaw pain, not drug related, reported by one participant. A decrease in bone mineral density (BMD) (median change from baseline: femur, $-2.09 \%$; lumbar vertebra, $-2.24 \%$ ) was observed at 96 weeks.

\section{Discussion}

This study is the first prospective study to investigate the efficacy and safety of switching to TDF from ETV, focusing on patients with $\mathrm{HBeAg}$-positive and $\mathrm{HBV}$ DNA undetectable $\mathrm{CHB}$ in Japan. Because the results of our previous phase 3 study in treatment-naïve participants showed that reduction in $\mathrm{HBsAg}$ observed in the TDF group was predominantly in HBeAg-positive patients [13], we targeted patients with $\mathrm{HBeAg}$-positive $\mathrm{CHB}$ (including five patients who were $\mathrm{HBeAg}$-positive according to local in-hospital laboratory results; Table 1) treated with ETV for at least two years in this phase 4 study. To ensure an adequate sample size of HBeAg positive $\mathrm{CHB}$ patients with undetectable serum HBV-DNA, the study was conducted as a multi-center trial.

While our data showed the switch to TDF was still virologically suppressive, the proportion of patients achieving $0.25 \log _{10} \mathrm{HBsAg}$ reduction from baseline at week 48 (4\%) was lower than our original assumption (20\%). This may be explained by the variation in duration of previous ETV treatment across the study population. Entecavir therapy for at least two years prior to screening was required, however, no upper limit was specified for duration of time on therapy and participant data were not collected in this regard. Previous studies have reported a greater rate of $\mathrm{HBsAg}$ reduction during the first year of NA therapy (ETV, TDF) compared with subsequent years [18]. Although we did not investigate the correlation between the duration of ETV therapy and HBsAg reduction in this study, it is possible that the duration of prior ETV therapy influenced the rate of patient achieving 0.25 $\log _{10}$ HBsAg reduction from baseline at week 48 .

Participants in this study with higher ALT levels $(\mathrm{N}=6$, defined as $\geq 60 \mathrm{U} / \mathrm{L}$ at least once from baseline through week 48), including the three participants with $0.25 \log _{10}$ $\mathrm{HBs} A g$ reduction from baseline at week 48 , had a numerically greater reduction from baseline in HBsAg level at both week 48 and week 96 versus those with lower 


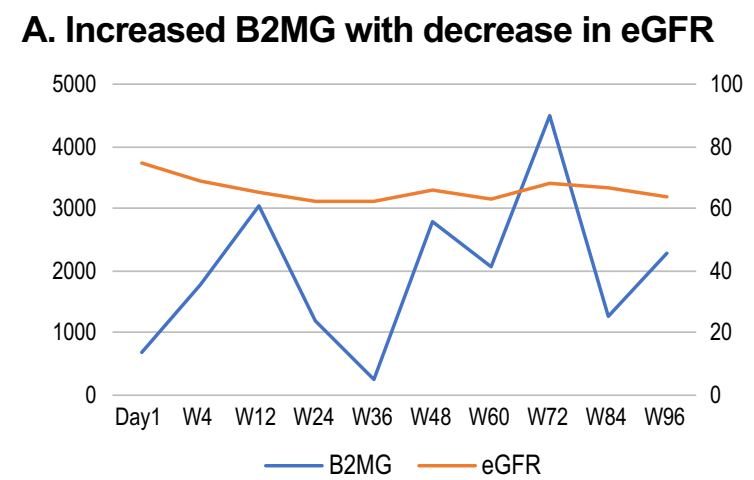

\section{B. Increased B2MG with no change in eGFR}

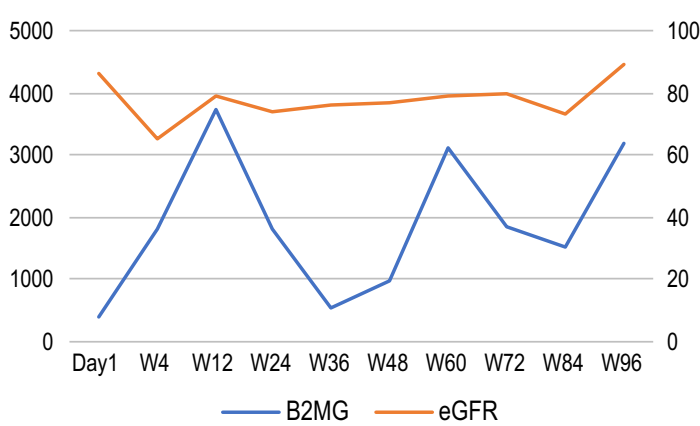

\section{No change in B2MG with decrease in eGFR}

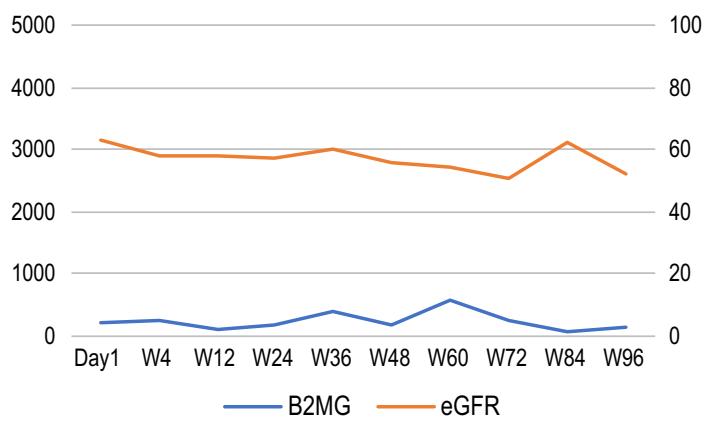

Fig. 4 Individual participant observed clinical course types: change in B2MG ( $\mu \mathrm{g} / \mathrm{g}$ creatinine) and eGFR $\left(\mathrm{mL} / \mathrm{min} / 1.73 \mathrm{~m}^{2}\right)$. B2MG, urine beta-2-microglobulin; $\mathrm{Cr}$, creatinine; eGFR, estimated glomerular filtration rate

ALT levels $(\mathrm{N}=67$, defined as $<60 \mathrm{U} / \mathrm{L}$ from baseline through week 48). This is similar to our previous study in naïve patients indicating that HBsAg reduction was predominant in patients with higher ALT levels $(\geq 80$ $\mathrm{U} / \mathrm{L}$ ) [13]. However, in terms of individual participants, there was no apparent pattern between ALT levels and HBsAg change from baseline for the nine participants in the current study who achieved $>0.25 \log _{10}$ reduction at 96 weeks. It is possible that a combination of factors (e.g., high ALT together with HBeAg-positive status and some unknown factors) is associated with HBsAg reduction after switching to TDF. As previously reported, higher serum IFN $\lambda 3$ levels were observed in patients treated with NAs (ADV and TDF), but not in those treated with NAs (lamivudine and ETV) [19]. Interferon- $\lambda 3$ induction caused by the NAs further induces IFN-stimulated genes and results in a reduction of $\mathrm{HBs} A g$ production. Although we did not measure serum IFN $\lambda 3$ levels in this study, greater HBsAg reduction in patients with higher ALT levels may be related to immunomodulatory effects associated with TDF therapy [20].

In this study, $25 \%$ of HBeAg-positive participants, with at least two years of prior ETV treatment, achieved $\mathrm{HBeAg}$ seroclearance up to 96 weeks after switching to TDF. The HBeAg seroclearance rate we observed was comparable to rates reported in previous studies in patients treated with ETV [21, 22]. In this limited number of participants, there was no apparent relationship between $\mathrm{HBeAg}$ status change and $\mathrm{HBcrAg}$ reduction.

No new safety concerns were identified with TDF therapy (including bone, liver, or renal AESIs) compared with previous studies [5, 8, 11, 13, 14]. Among participants with a decrease in BMD, no apparent common trends were observed, such as a reduction in serum phosphate or \%TRP, and there were no apparent associated common factors. Overall, decreases in BMD were consistent with historical data for participants with HBV and the known safety profile of TDF therapy [23]. There was no apparent link between changes in BMD and other renal parameters measured in the current study. Observed increases in serum creatinine and decreases in eGFR were also comparable to previous studies $[8,11,14]$, and therefore, continuous monitoring for bone and renal events is necessary during treatment with TDF.

The percentage of participants with ALT above the upper limit of normal (>40 U/L) increased to $14 \%$ at week 48 from $8 \%$ at baseline, although it is unclear if the lack of ALT normalization was due to TDF therapy [11]. We also carefully monitored urine beta-2-microglobulin to creatinine ratio and \%TRP. Although urine beta-2-microglobulin to creatinine ratio and \%TRP are considered sensitive and specific indicators of renal tubular dysfunction associated with long-term use of TDF $[8,16]$, no consistent trends were apparent in the current study between changes in these early indicators of kidney injury and other renal parameters such as eGFR. An increase in urine beta-2-microglobulin was not always accompanied by a change in eGFR and some participants had a decrease in eGFR with no change in urine beta-2-microglobulin. These observations suggest that urine beta-2-microglobulin may not be a sensitive marker for predicting renal dysfunction. 
This study has several limitations that should be considered. In previous studies, HBsAg levels have been shown to decline with ETV treatment [21, 22, 24, 25]. Because there was no control arm in this study due to feasibility constraints, it was not clearly shown that the HBsAg decline (4\% responder rate, mean $0.11 \log _{10} \mathrm{IU} /$ $\mathrm{mL}$ decline from baseline) observed at week 48 was attributed to TDF switch therapy. Another limitation is that most of the patients in the current study had genotype $\mathrm{C}$, whereas HBsAg loss occurs more often and declines in $\mathrm{HBsAg}$ are greater in $\mathrm{HBeAg}+$ patients with genotype A or D infection [4]. Finally, patients with clinically significant renal impairment (creatinine clearance $<70 \mathrm{~mL} / \mathrm{min}$ ) were not assessed, which could have biased renal outcomes in this study.

\section{Conclusions}

Although switching from ETV to TDF remained virologically suppressive with no significant safety concerns, our analysis did not clearly show an additional clinical benefit of switching from ETV to TDF in $\mathrm{HBeAg}$-positive and HBV-DNA undetectable CHB patients. Nevertheless, our analysis suggests that there are additional patient factors impacting HBsAg reduction. Evaluation of liver damage and its reversibility with $\mathrm{CHB}$ treatment are important clinical questions that were not addressed in the current study which was focused on virological response. Further investigation is needed to better understand the clinical impact of switching from ETV to TDF. Our study also indicates a need for further development of HBV therapies with a novel mechanism for HBsAg reduction and seroclearance.

\section{Abbreviations}

ADV: Adefovir dipivoxil; AE: Adverse event; AESI: Adverse event of special interest; ALT: Alanine aminotransferase; BMD: Bone mineral density; CHB: Chronic hepatitis B; eGFR: Estimated glomerular filtration rate; ETV: Entecavir; $\mathrm{HBCrAg}$ : Hepatitis B core-related antigen; FAS: Full analysis set; HBeAg: Hepatitis B e-antigen; HBsAg: Hepatitis B surface antigen; HBV: Hepatitis B virus; HCV: Hepatitis C virus; HCC: Hepatocellular carcinoma; IFN: Interferon; NA: Nucleos(t)ide analogue; TAF: Tenofovir alafenamide; TDF: Tenofovir disoproxil fumarate; TRP: Renal tubular reabsorption of phosphate.

\section{Acknowledgements}

All listed authors meet the criteria for authorship set forth by the International Committee for Medical Journal Editors. Editorial support was provided by Allyson Lehrman, DPM (assembling tables and figures, collating author comments, copyediting, fact checking, and referencing) and graphic services were provided by AOIC, LLC and were funded by GSK.

\section{Authors' contributions}

Study concept and design: FS, YT, MK1, HY, HI, YS2, WS. Acquisition of data: FS, YS1, YK1, YT, MK1, HY, TA, MA, TW, ME, NM, HK1, KJ, KM1, KM2, KT, TI, SF, TK, HI, HK2. Analysis and interpretation of data: FS, YS1, YK1, YT, MK1, HY, TA, MA, TW, ME, MK2, NM, HK1, KJ, KM1, KM2, KT, TI, SF, TK, HI, ST, YS2, YK2, WS, HK2. Drafting of the manuscript: All authors provided critical revision of the manuscript for important intellectual content. Statistical analysis: HI. Obtained funding: WS Study supervision: HK2. All authors approved the submitted manuscript and agreed to be accountable for all aspects of the work. All authors read and approved the final manuscript.

\section{Funding}

Funding for this study (NCT03258710 available from www.clinicaltrials.gov) was provided by GlaxoSmithKline (GSK). Authors who are employees of GSK were involved in the concept and design of the study, the acquisition of data, the analysis and interpretation of the data, drafting of the manuscript, commenting critically, and approval to submit.

\section{Availability of data and materials}

The datasets used and/or analyzed during the current study can be requested for further research. Within 6 months of this publication, anonymized individual participant data, the annotated case report form, protocol, reporting and analysis plan, data set specifications, raw dataset, analysis-ready dataset, and clinical study report will be available for research proposals approved by an independent review committee. Proposals should be submitted to www. clinicalstudydatarequest.com. A data access agreement will be required.

\section{Declarations}

\section{Ethics approval and consent to participate}

The study was approved by the ethics committee at every participating institution (Ehime Prefectural Central Hospital IRB, Ehime, Japan; Kindai University Hospital IRB, Osaka, Japan; Kitakyushu Municipal Medical Center IRB, Fukuoka, Japan; KKR Clinical Trial Network Central Institutional Review Board, Tokyo, Japan; Kumamotoshinto General Hospital IRB, Kumamoto, Japan; Kurume University Hospital IRB, Fukuoka, Japan; Matsuyama Red Cross Hospital IRB, Ehime, Japan; Musashino Red Cross Hospital IRB, Tokyo, Japan; Nagoya City University Graduate School of Medical Sciences and Nagoya City University Hospital Institutional Review Board, Aichi, Japan; National Hospital Organization Kure Medical Center and Chugoku Cancer Center IRB, Hiroshima, Japan; National Hospital Organization Nagasaki Medical Center IRB, Nagasaki, Japan; Nippon Medical School Chiba Hokusoh hospital IRB, Chiba, Japan; Obihiro-Kosei General Hospital IRB, Hokkaido, Japan; Osaka City University Hospital IRB, Osaka, Japan; Sanin Rosai Hospital IRB, Tottori, Japan; Sapporo-Kosei General Hospital IRB, Hokkaido, Japan; St. Marianna University Group Institutional Review Board, Kanagawa, Japan) and was conducted according to the recommendations of Good Clinical Practice and the Declaration of Helsinki (2013). All participants provided written informed consent to participate in the study. This manuscript was developed following the CONSORT guidelines as much as possible even through this is not a randomized control trial.

\section{Consent for publication}

Not Applicable.

\section{Competing interests}

This study (NCT03258710) was conducted with a research fund from GlaxoSmithKline (GSK), in which FS, YS1, YK1, TA, MA, MK1, TW, YT, ME, MK2, NM, HK1, KJ, KM1, KM2, KT, TI, HY, SF, and HK2 participated as investigators and their institutions received funding in relation to this work. FS has served on the advisory board for GSK, and has received personal fees from AbbVie Inc., Bristol Myers Squibb, and GSK; YT has served on several advisory boards for GSK, has received personal fees from Fujirebio Inc., GSK, and Sysmex Corporation, has received personal fees and grants from Gilead Sciences Inc. and grants from FUJIFILM Corporation and Janssen Pharmaceutical KK, and has served on the Board of Trustees of the Leland Stanford Junior University; MK1 and HY have served on the advisory board for GSK, and have received personal fees from GSK; TA has received grants and personal fees from AbbVie Inc.; MA has received grants and personal fees from AbbVie Inc., and Merck Sharp \& Dohme (MSD); KJ has received speaking fees from AbbVie Inc., Gilead Sciences, Inc., MSD, and Otsuka Pharmaceutical Co., Ltd.; TK, HI, YS2, and YK2 are employees of and own stock in GSK; ST is employee of GSK; WS is a former employee of GSK; HK2 has served as a speaker and trainer for AbbVie Inc., Eisai Co. Ltd, Gilead Sciences, Inc., MSD KK, and Sumitomo Dainippon Pharma.

\section{Author details}

${ }^{1}$ Toranomon Hospital Kajigaya, 1-3-1, Kajigaya, Takatsu-ku, Kawasaki-city, Kanagawa 213-8587, Japan. ${ }^{2}$ Toranomon Hospital, 2-2-2, Toranomon, Minato-ku 105-8470, Japan. ${ }^{3}$ Sapporo-Kosei General Hospital, 8-5, Kita 3-jo 
Higashi, Chuo-ku, Sapporo-city, Hokkaido 060-0033, Japan. ${ }^{4}$ Nagoya City University Hospital, 1, Aza-Kawasumi, Mizuho, Nagoya, Aichi 467-8602, Japan. ${ }^{5}$ Musashino Red Cross Hospital, 1-26-1, Kyonan-cho, Musashino-shi, Tokyo 180-8610, Japan. ${ }^{6}$ National Hospital Organization Nagasaki Medical Center, 2-1001-1, Kubara, Omura-city, Nagasaki 856-8562, Japan. ' ObihiroKosei General Hospital, 10-1, Nishi 14-jo Minami, Obihiro-city, Hokkaido 080-0024, Japan. ${ }^{8}$ Nippon Medical School Chiba Hokusoh Hospital, 1715, Kamakari, Inzai-City, Chiba 270-1694, Japan. ${ }^{9}$ St. Marianna University School of Medicine Hospital, 2-16-1, Sugao, Miyamae-ku, Kawasaki-city, Kanagawa 216-8511, Japan. ${ }^{10}$ Osaka City University Hospital, 1-5-7, Asahi-machi, Abeno-ku, Osaka-city, Osaka 545-8586, Japan. ${ }^{11}$ Kindai University Hospital, 377-2, Ohnohigashi, Osakasayama-city, Osaka 589-8511, Japan. ${ }^{12}$ Sanin Rosai Hospital, 1-8-1, Kaikeshinden, Yonago-city, Tottori 683-8605, Japan. ${ }^{13}$ National Hospital Organization Kure Medical Center and Chugoku Cancer Center, 3-1, Aoyama-cho, Kure-city, Hiroshima 737-0023, Japan. ${ }^{14}$ Matsuyama Red Cross Hospital, 1, Bunkyo-cho, Matsuyama-city, Ehime 790-8524, Japan.

${ }^{15}$ Ehime Prefectural Central Hospital, 83, Kasugamachi, Matsuyama-city, Ehime 790-0024, Japan. ${ }^{16}$ Kitakyushu City Hospital Organization Kitakyushu Municipal Medical Center, 2-1-1, Bashaku, Kokurakita-ku, Kitakyushu-city, Fukuoka 802-0077, Japan. ${ }^{17}$ Hamanomachi Hospital, 3-3-1, Nagahama, Chuo-ku, Fukuoka-city, Fukuoka 810-8539, Japan. ${ }^{18}$ Kurume University Hospital, 67, Asahi-machi, Kurume-shi, Fukuoka 830-0011, Japan. ${ }^{19}$ Kumamoto Shinto General Hospital, 3-2-65, Ooe, Chuo-ku, Kumamoto-city, Kumamoto 862-8655, Japan. ${ }^{20} \mathrm{GlaxoSmithKline} \mathrm{K.K.,} \mathrm{Akasaka} \mathrm{Intercity} \mathrm{AIR,} \mathrm{1-8-1,} \mathrm{Akasaka,} \mathrm{Minato-ku,}$ Tokyo 107-0052, Japan. ${ }^{21}$ National Center for Global Health and Medicine, 1-21-1 Toyama Shinjuku-ku, Tokyo 162-8655, Japan. ${ }^{22}$ Present Address: Keiyukai Sapporo Hospital, 1-1, Kita, Hondori 14 chome, Shiroishi-ku, Sapporo-city, Hokkaido 003-0027, Japan. ${ }^{23}$ Present Address: Kumamoto University, 1-1-1 Honjo, Chuo-ku, Kumamoto 860-8556, Japan. ${ }^{24}$ Present Address: Shin-Eikai Hospital, 12-11, Bentencho, Kokurakita-ku, Kitakyushu-city, Fukuoka 803-0856, Japan.

Received: 22 December 2020 Accepted: 2 November 2021 Published online: 20 December 2021

\section{References}

1. Lai CL, Ratziu V, Yuen MF, Poynard T. Viral hepatitis B. Lancet. 2003;362(9401):2089-94.

2. Chen LP, Zhao J, DuY, et al. Antiviral treatment to prevent chronic hepatitis B or C-related hepatocellular carcinoma. World J Virol. 2012;1(6):174-83.

3. Kim WR, Loomba R, Berg T, et al. Impact of long-term tenofovir disoproxil fumarate on incidence of hepatocellular carcinoma in patients with chronic hepatitis B. Cancer. 2015;121(20):3631-8.

4. Seo Y, Yano Y. Short- and long-term outcome of interferon therapy for chronic hepatitis B infection. World J Gastroenterol. 2014;20(37):13284-92.

5. Marcellin P, Heathcote EJ, Buti M, et al. Tenofovir disoproxil fumarate versus adefovir dipivoxil for chronic hepatitis B. N Engl J M. 2008;359(23):2442-55.

6. Yip TC, Wong GL, Chan HL, et al. HBsAg seroclearance further reduces hepatocellular carcinoma risk after complete viral suppression with nucleos(t)ide analogues. J Hepatol. 2019;70(3):361-70.

7. Gish RG, Given BD, Lai CL, et al. Chronic hepatitis B: virology, natural history, current management and a glimpse at future opportunities. Antiviral Res. 2015;121:47-58.

8. Chan HL, Fung S, Seto WK, et al. Tenofovir alafenamide versus tenofovir disoproxil fumarate for the treatment of HBeAg-positive chronic hepatitis $B$ virus infection: a randomised, double-blind, phase 3, non-inferiority trial. Lancet Gastroenterol Hepatol. 2016;1 (3):185-95.

9. Tamaki N, Kurosaki M, Kirino S, et al. Hepatitis B surface antigen reduction as a result of switching from long-term entecavir administration to tenofovir. JGH Open. 2019;4(3):429-32.

10. Yang $\mathrm{S}, \mathrm{Ma} X, \mathrm{Cai} \mathrm{C}$, Wang H, Xiao F, Yu C. Tenofovir disoproxil fumarate is superior to entecavir in reducing hepatitis B surface antigen for chronic hepatitis B in China: 2-year comprehensive comparative result of a matched comparative study. Front Med (Lausanne). 2021;8:637126.
11. lida-Ueno A, Enomoto M, Kozuka R, Tamori A, Kawada N. Switching to tenofovir disoproxil fumarate vs continuing treatment in patients with chronic hepatitis B who maintain long-term virological response to entecavir therapy: a randomized trial. J Med Virol. 2019;91(7):1295-300.

12. Choi J, Kim HJ, Lee J, Cho S, Ko MJ, Lim YS. Risk of hepatocellular carcinoma in patients treated with entecavir vs tenofovir for chronic hepatitis B: a Korean nationwide cohort study. JAMA Oncol. 2019;5(1):30-6.

13. Koike K, Suyama K, Ito H, Itoh H, Sugiura W. Randomized prospective study showing the non-inferiority of tenofovir to entecavir in treatmentnaive chronic hepatitis B patients. Hepatol Res. 2018;48(1):59-68.

14. Yim HJ, Kim IH, Suh SJ, et al. Switching to tenofovir vs continuing entecavir for hepatitis B virus with partial virologic response to entecavir: a randomized controlled trial. J Viral Hepat. 2018;25(11):1321-30.

15. Martinot-Peignoux M, Asselah T, Marcellin P. HBsAg quantification to optimize treatment monitoring in chronic hepatitis B patients. Liver Int. 2015;35(Suppl 1):82-90.

16. Kinai $E$, Hanabusa H. Progressive renal tubular dysfunction associated with long-term use of tenofovir DF. AIDS Res Hum Retroviruses. 2009;25(4):387-94.

17. Shea PH, Maher JF, Horak E. Prediction of glomerular filtration rate by serum creatinine and beta 2-microglobulin. Nephron. 1981;29(1-2):30-5.

18. Seto WK, Liu K, Wong DK, et al. Patterns of hepatitis B surface antigen decline and HBV DNA suppression in Asian treatment-experienced chronic hepatitis B patients after three years of tenofovir treatment. J Hepatol. 2013;59(4):709-16.

19. Murata K, Asano M, Matsumoto A, et al. Induction of IFN-lambda3 as an additional effect of nucleotide, not nucleoside, analogues: a new potential target for HBV infection. Gut. 2018;67(2):362-71.

20. Wong $D$, Littlejohn $M$, Edwards R, et al. ALT flares during nucleotide analogue therapy are associated with HBsAg loss in genotype A HBeAgpositive chronic hepatitis B. Liver Int. 2018;38(10):1760-9.

21. Seto WK, Lam YF, Fung J, et al. Changes of HBsAg and HBV DNA levels in Chinese chronic hepatitis B patients after 5 years of entecavir treatment. J Gastroenterol Hepatol. 2014;29(5):1028-34.

22. Suzuki F, Hosaka T, Suzuki Y, et al. Long-term outcome of entecavir treatment of nucleos(t)ide analogue-naive chronic hepatitis B patients in Japan. J Gastroenterol. 2019;54(2):182-93.

23. Wei MT, Nguyen MH, Cheung R. Epidemiology, diagnosis, and management of bone disease in patients with chronic HBV infection. Curr Hepatol Rep. 2019;18:322-30.

24. Li M-R, Xi H-L, Wang Q-H, et al. Kinetics and prediction of HBsAg loss during long-term therapy with nucleos(t)ide analogues of different potency in patients with chronic hepatitis B. PLoS One. 2014;9(6):e98476.

25. Hara T, Suzuki F, Kawamura Y, et al. Long-term entecavir therapy results in falls in serum hepatitis B surface antigen levels and seroclearance in nucleos(t)ide-naive chronic hepatitis B patients. J Viral Hepat. 2014;21(11):802-8.

\section{Publisher's Note}

Springer Nature remains neutral with regard to jurisdictional claims in published maps and institutional affiliations. 